\title{
Educação de Jovens e Adultos, Multisseriação e Recursos Didáticos Digitais: uma tentativa de diálogo
}

\author{
Young People and Adult Education, Multigraded Teaching and Digital \\ Learning Resources: an attempt dialogue
}

\section{Gabriel Moreira Beraldi}

Doutorando em Ensino de Biociências e Saúde (IOC-Fiocruz); Docente na SEEDUC-RJ e Escola Firjan SESI.

gabscj@yahoo.com.br - http://orcid.org/0000-0001-8786-9179

\section{Francisco Roberto Pinto Mattos}

Doutor em Engenharia de Sistemas e Computação (UFRJ); Docente do ensino básico, técnico e tecnológico e Coordenador do Mestrado Profissional em Práticas para a Educação Básica no Colégio Pedro II e docente do Mestrado Profissional PROFMAT da UERJ.

francisco.mattos@gmail.com - https://orcid.org/0000-0003-3760-4636

\section{Aira Suzana Ribeiro Martins}

Doutora em Letras (UERJ); Docente do Ensino básico, técnico e tecnológico e Supervisora do Programa de Residência Docente no Colégio Pedro II.

airasuzana.ribeiromartins@gmail.com - https://orcid.org/0000-0002-5917-1870

Recebido em 30 de setembro de 2018

Aprovado em 30 de outubro de 2019

Publicado em 17 de dezembro de 2019

\section{RESUMO}

O presente trabalho pretende responder à seguinte pergunta de investigação: "De que forma a Educação de Jovens e Adultos multisseriada, aliada ao uso de tecnologias, pode contribuir para o processo ensino-aprendizagem?". Para tanto, tem como objetivo investigar as contribuições da multisseriação e da utilização de recursos didáticos digitais no processo ensino-aprendizagem do aluno da EJA. Regulada por uma legislação específica, a EJA tem sido difundida nos últimos anos como importante ferramenta de inclusão. Em algumas instituições, no entanto, ela está aliada à realidade da multisseriação, que comporta alunos de diferentes séries em uma mesma sala de aula. Pesquisas recentes mostram os desafios dos docentes no trabalho em turmas da EJA. Esta pesquisa é de cunho qualitativo e se utilizou de pesquisa bibliográfica e entrevistas semiestruturadas em uma amostra de 20 alunos de Ensino Médio multisseriado da modalidade EJA de uma das unidades da Escola SESI/RJ. As conclusões apontaram para uma avaliação positiva da junção entre EJA, multisseriação e recursos didáticos digitais.

Palavras-chave: Educação de Jovens e Adultos; Multisseriação; Recursos didáticos digitais. 


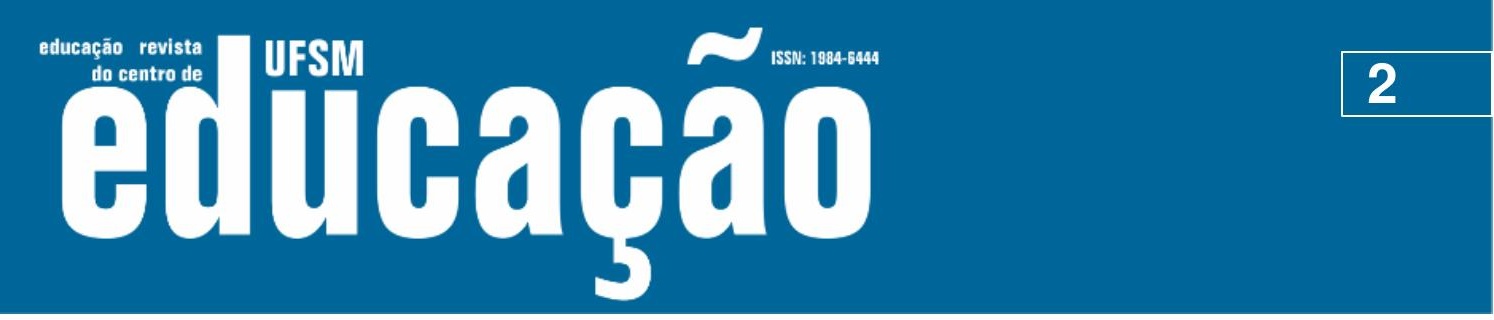

ISSN: 1984-6444 | http://dx.doi.org/10.5902/1984644434990

\section{ABSTRACT}

This paper aims to answer the following research question: "How can multigraded classes of the Youth and Adult Education, combined with the use of technologies, contribute to the teaching-learning process?". To do so, it aims to investigate the contributions of multigrade classes and the use of digital didactic resources in the teaching-learning process of the student of the Young and People Education. Regulated by specific legislation, Young People and Adult Education has been widespread as an important means of inclusion in recent years. However, in some institutions it is allied to the reality of multigraded teaching, which involves students from different grades in the same classroom. Recent research, shows the challenges faced by teachers in working Young People and Adult classes. This research is qualitative and it was used a bibliographic research and semi-structured interview in a sample of 20 high school students of multigraded classes of the Youth and Adult Education modality of one branch of the SESI/RJ School. The conclusions pointed to a positive evaluation of the junction between EJA, multiseriate and digital didactic resources.

Keywords: Young People and Adult Education; Multigraded teaching; Digital learning resources.

\section{Introdução}

Turmas de Educação de Jovens e Adultos (doravante EJA), mesmo tendo recebido nos últimos anos grande atenção da legislação nacional (OLIVEIRA, 2011) são, por si só, desafiantes para docentes e discentes, uma vez que trazem consigo peculiaridades que necessitam ser compreendidas e enfrentadas. Segundo Candau (2007), esse paradoxo surge, por um lado, devido à expansão da educação básica nos últimos anos; em contrapartida, índices como os de evasão e repetência persistem, sem que seja efetivamente problematizada a questão da qualidade educacional e da própria valorização do professor. De acordo com Jesus e Machado (2011), o termo Educação de Jovens e Adultos é recente, mas uma preocupação mais refinada sobre a educação no país remonta à "Campanha de Educação de Adultos", de 1947. A partir de fins da década de 1950, através da influência de Paulo Freire, surgem reflexões sobre a questão do analfabetismo e do desejo de um novo paradigma pedagógico que se baseasse na visão de mundo e nos componentes socioculturais dos indivíduos. Segundo o pesquisador, "a leitura do mundo precede a 


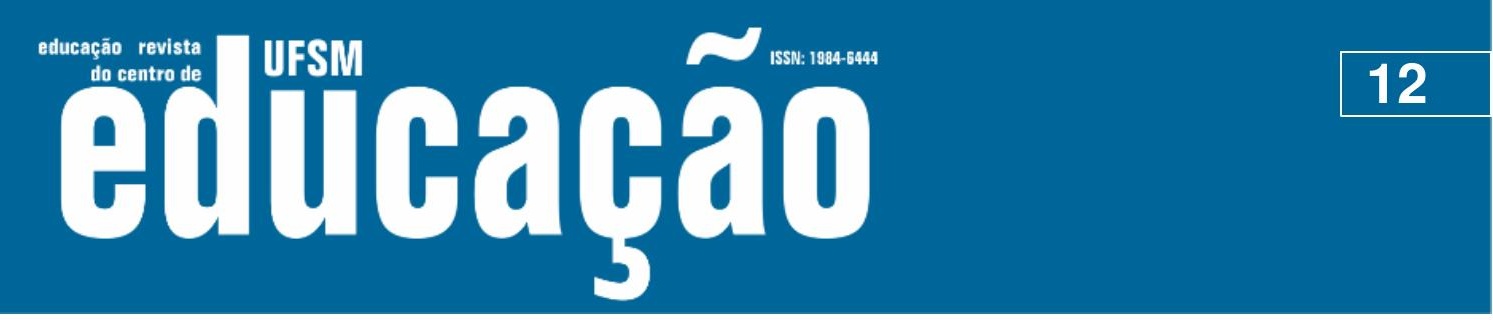

ISSN: 1984-6444 | http://dx.doi.org/10.5902/1984644434990

\section{A palavra dos alunos}

O objeto desta investigação é a EJA multisseriada que se utiliza de recursos didáticos digitais no processo ensino-aprendizagem. O Centro de Estudos Santa Luzia, da rede SESI-RJ, além de oferecer esta modalidade de ensino, fomenta a utilização de tecnologias em sala de aula. Dessa forma, os alunos entrevistados foram instados a avaliar as contribuições da multisseriação e das tecnologias em suas aprendizagens dentro da EJA.

Dos 20 alunos pesquisados, 12 são do sexo feminino e 8 do masculino. Ressalte-se que todos os alunos entrevistados são maiores de 18 anos. $\mathrm{Na}$ transcrição dos relatos, os alunos foram identificados como aluno A1 a A20, com informação do sexo e da idade de cada um. Alguns depoimentos procuram relacionar a EJA à multisseriação e às tecnologias, no entanto, outros abordam apenas dois ou um dos itens. O primeiro relato desenvolve a questão da EJA com as tecnologias.

De maneira geral, os diálogos revelaram um sentimento quase que de gratidão pela existência da EJA, de respaldo à importância do uso de tecnologias e de desconfiança com relação à multisseriação. Isso fica evidente nas falas abaixo:

A EJA recuperou a minha autoestima. Me sentia mal por não ter completado
os estudos. Me culpava por isso. Me sentia incapaz. Agora me sinto completo.
Um cidadão. [...] Ainda fico um pouco confuso com esse lance das três séries
juntas, mas acho que vou me acostumar. [...] A EJA me ajuda bastante a
aprender rápido e a aprender pela internet, afinal, hoje em dia tudo está na
net, não é mesmo? Eu consigo aprender da mesma forma que em uma escola
"normal"; aqui eles só reduzem mais, mas ensinam da mesma forma, fazendo
ser bem mais prático e fácil de entender. (Aluno A10, mulher, 20 anos)

A EJA é vista como a possibilidade de voltar a estudar e de "recuperar o tempo perdido". Trata-se de um reconhecimento, ainda que inconsciente em muitos casos, do direito à educação. Além disso, pôde-se perceber, mesmo de forma tímida, um sentido de inclusão e de uma nova forma de pertença à sociedade.

O uso de tecnologias como recursos didáticos reforçam esse sentimento de inclusão por trazerem para a sala de aula algo do cotidiano. A escola não mais é vista como um espaço separado do "resto da sociedade", mas como parte dela. Os entrevistados também apontaram para o benefício da utilização de smartphones em sala de aula. Ou seja, os celulares, antes vistos como vilões são explorados pelos 


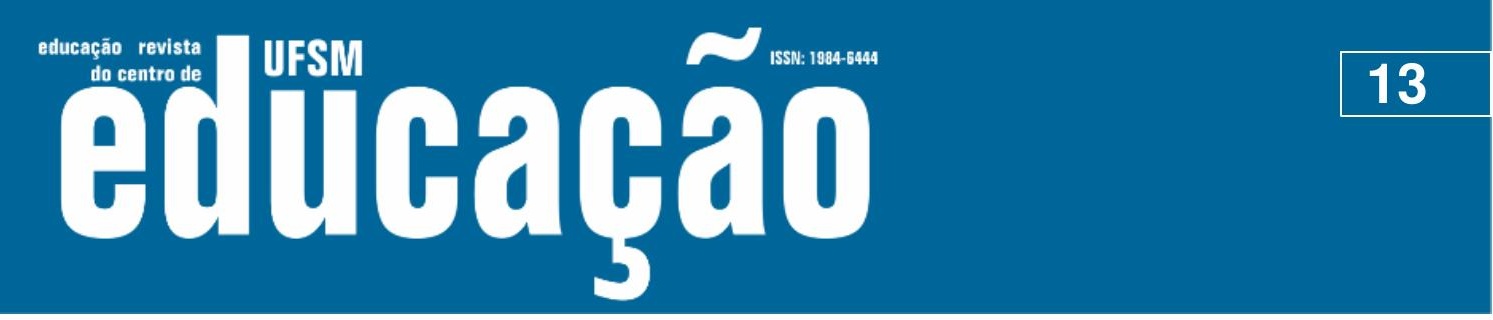

ISSN: 1984-6444 | http://dx.doi.org/10.5902/1984644434990

professores como forma de auxílio no processo ensino-aprendizagem.

A minha opinião é que, quando usamos o celular na aula, ela fica mais dinâmica. Ainda mais aqui na EJA, que o tempo é mais curto. A gente aproveita melhor o tempo e aprende usando algo que faz parte do nosso cotidiano. (Aluno A3, homem, 18 anos)

$\mathrm{Na}$ teoria a questão da tecnologia funciona. Porém, na prática, não. Os professores são excelentes, mas são eles que fazem as aulas acontecerem. Claro que a tecnologia em sala de aula ajuda, porém não é tudo. (Aluno A1, homem, 20 anos)

Por outro lado, algumas poucas, porém significativas, críticas às tecnologias foram tecidas; todas elas à exceção de uma, feitas por alunos com mais de 30 anos. Uma preocupação recorrente deles é o fato de, com os recursos digitais, escreverem menos. Uma hipótese para explicar esse fenômeno talvez seja uma visão tradicional, enraizada em nossa cultura escolar, de que só há aula quando há "matéria no caderno", desconsiderando, assim, a possibilidade de outras formas de aprendizagem.

A intenção é boa, mas na prática é ruim. Como eu vou aprender Matemática se eu não acompanhar o raciocínio que o professor vai passando no quadro? Existem matérias em que é muito difícil aprender se não copiar a matéria no caderno. Depois, como eu vou estudar para a prova? Fica difícil. Se fosse nas Humanas, até que a tecnologia pode ajudar, com vídeos etc. Em outras matérias acho que complica. (Aluno A19, homem, 39 anos)

O sistema EJA é de uma maneira geral uma boa opção para muitos estudantes que deixaram os estudos e tem pressa em concluí-los. O tempo é o maior inimigo da EJA; há conteúdo, mas pouco tempo para ser alcançado. $O$ fato de haver vários equipamentos em sala de aula favorece a qualidade do ensino, porém, diminui o conteúdo escrito. A digitalização trouxe uma comodidade e uma banalização ao ensino de tempos atrás. Pouco se lê e se escreve [...]. Infelizmente se perde o hábito de ler o conteúdo e fazer sua própria análise dos fatos [...]. (Aluno A13, mulher, 39 anos)

Sobre as classes multisseriadas, os depoimentos se mostraram muitas vezes confusos, sobretudo, pelo fato de os alunos não compreenderem, com clareza, a proposta da modalidade. Muitas críticas foram tecidas à instituição que sediou a pesquisa, pelo fato de não esclarecerem satisfatoriamente o próprio significado do termo multisseriação e sua funcionalidade. Tais críticas foram encaminhadas à referida instituição como forma de feedback.

Por outro lado, três entrevistados pontuaram possíveis vantagens da multisseriação, como a aprendizagem colaborativa a partir do contato com colegas de séries mais avançadas. Em contrapartida foi sinalizada a dificuldade de alguns 


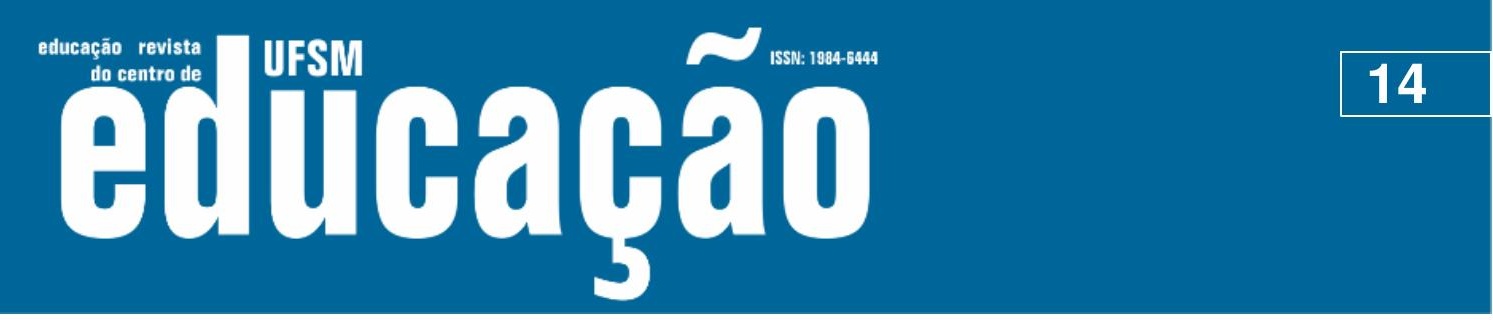

ISSN: 1984-6444 | http://dx.doi.org/10.5902/1984644434990

docentes em organizar as aulas e a própria disposição dos alunos em sala.

Eu até entendo que é legal a classe ser multisseriada, mas tem que organizar melhor. Eu gosto quando nos juntamos para trabalhos em grupo. Um ajuda o outro. Mas às vezes, nem o professor consegue organizar direito a sala. Divide o quadro em três e dá aula como se fosse pra uma série só. Aí seria melhor não juntar (as três séries em uma sala). (Aluno A7, homem, 28 anos)

Esse sistema facilita a vida da pessoa pelo fato de terminar duas séries em um ano. [...] Acho bom que tenha todos os anos em uma turma; conhecemos mais pessoas e também vamos aprendendo matérias mais avançadas. [...] É legal ter uma sala específica para certas matérias. (Aluno A17, homem, 21 anos)

O sistema de ensino EJA, para mim, é um sistema que me ajuda muito. A questão multisseriada nos permite interagir com pessoas com pensamentos variados e nos permite ter ideias e ensinamentos diferentes. Os recursos tecnológicos, creio que sejam importantes para desenvolvermos outras formas de aprendizagem, além do que a tendência no futuro é serem ainda mais utilizados em sala de aula. (Aluno A15, homem, 31 anos)

Em seguida apresentamos o relato de dois alunos que elogiam a EJA e o uso de tecnologias em sala de aula, fazendo críticas à questão da multisseriação.

O sistema EJA de educação é um grande projeto, pois facilita as pessoas que têm dificuldade em ir à escola; possui um período mais curto que é bem aproveitado, pecando apenas na questão da multisseriação, pois temos mais de uma série em uma mesma sala de aula, deixando o aluno um pouco perdido no início. A tecnologia é uma coisa muito boa, pois ajuda alunos e professores. (Aluno A2, homem, 22 anos)

Um programa bom que acelera os estudos daqueles que deixaram de estudar por algum motivo pessoal, dando oportunidade de terminar os estudos e alcançar seus objetivos, dando uma nova chance para nunca desistir, pois nunca é tarde. A multisseriação não ajuda muito, atrapalha demais. Não acho certo colocar três séries na mesma sala, pois o aprendizado não é o mesmo. A atenção não é a mesma, fica até um pouco complicado de aprender. A sala fica um pouco desorganizada, pois as séries são diferentes e os trabalhos, provas, não devem ser os mesmos. Então às vezes dificulta; acharia melhor separar por séries [...]. (Aluno A14, mulher, 20 anos)

De modo geral, podemos perceber que os alunos se sentem muito confortáveis e incluídos com a EJA. Podemos também perceber uma satisfação com o uso das tecnologias. A multisseriação, no entanto, divide opiniões e é necessário que haja uma reflexão docente acerca do assunto. O professor deve deixar bem claro aos alunos como funciona essa metodologia e seus objetivos. Um erro muito comum, nesse caso, é trabalhar nas classes multisseriadas como se trabalha nas seriadas, fragmentando o conhecimento e subdividindo a turma de acordo com as séries. 


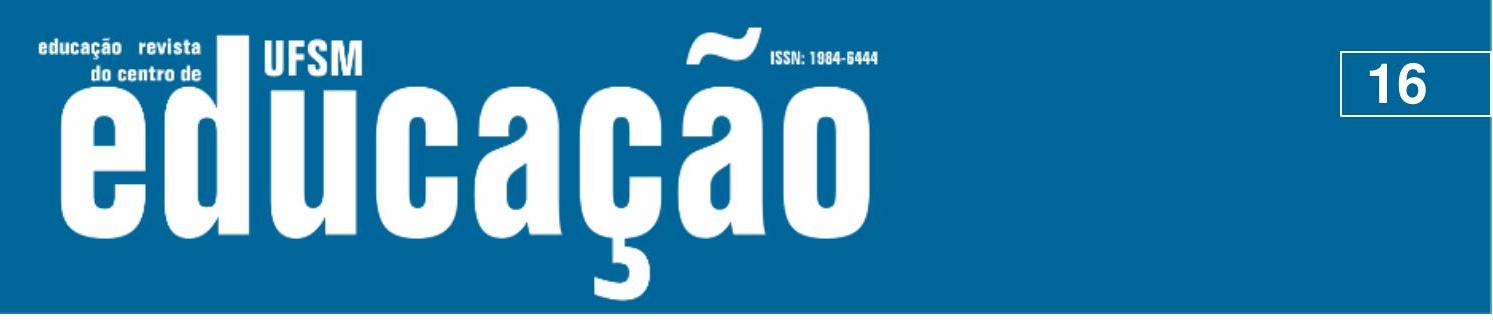

ISSN: 1984-6444 | http://dx.doi.org/10.5902/1984644434990

metodologia e melhor avaliar sua eficácia.

\section{Referências}

ANDRADE, Maria Margarida de. Introdução à Metodologia do Trabalho Científico: elaboração de trabalhos na graduação. 8. ed. São Paulo: Atlas, 2007.

BEHRENS, Marilda Aparecida. 0 paradigma emergente e a prática pedagógica. Curitiba: Champagnat, 1999.

BERRY, Chris. Multigrade Teaching: a discussion document. 2010. Disponível em http://www.ioe.ac.uk. Acesso em 12 de setembro de 2018.

BRASIL. Diretrizes e Bases da Educação Nacional. Lei oํ 9.393/96. Diário Oficial da União, 20/12/1996.

CAMINHA, Ivanete Saskoski; OLIVEIRA, Adriana Leônidas de. Características da Educação de Jovens e Adultos na percepção de egressos matriculados no Ensino Superior. In: X Encontro Latino Americano de Pós Graduação. São José dos Campos-SP. Mostra Científica - UNIVAP - X Encontro Latino Americano de Pós Graduação, 2010.

CANDAU, Vera Maria. Construir ecossistemas educativos - reinventar a escola. In: CANDAU, Vera Maria (org.). Reinventar a escola. 5 Ed. Petrópolis: Vozes, 2007. p. 11-16.

FERRI, Cassia. Classes multisseriadas: que espaço escolar é esse? $1994.166 \mathrm{f}$. Dissertação (Mestrado em Educação) - Centro de Ciências da Educação, Universidade Federal de Santa Catarina, Florianópolis, 1994.

FREIRE, Paulo. A importância do ato de ler. 45ํㅡㄹ ed. São Paulo: Cortez, 2003.

INEP - INSTITUTO NACIONAL DE PESQUISAS EDUCACIONAIS ANÍSIO TEIXEIRA. Panorama da educação no campo. Brasília: INEP, 2007.

JESUS, Eliângela Ferreira de; MACHADO, Liliane Campos. Reflexões sobre a proposta curricular da Educação de Jovens e Adultos. In: III Congresso NorteMineiro de Pesquisa em Educação: Diferentes Linguagens na Formação do Professor. 2011, Montes Claros. Anais. Montes Claros: Unimonte, 2011. v. 1. p. 1-22.

LEMOS, Marlene Emília Pinheiro de. Proposta Curricular. In: BRASIL. Salto para o futuro: Educação de Jovens e Adultos. Brasília: Ministério da Educação. SEED, 1999. Vol. 10, p. 19-25, 112p.

OLIVEIRA, Rita de Cássia da Silva. EJA em Ponta Grossa: Características do Público Discente. Revista HISTEDBR Online. Campinas. n. 41, p. 255-269, mar. 2011. 


\section{uss Fullaghã}

ISSN: 1984-6444 | http://dx.doi.org/10.5902/1984644434990

ROSA, Ana Cristina Silva da. Classes multisseriadas: desafios e possibilidades. In: Educação \& Linguagem. Ano 11, n. 18, p. 222-237, jul./dez. 2008.

SOUSA, Kesia Costa.; CUNHA, Nathan da Silva. Perfil dos alunos da Educação de Jovens e Adultos de Teresina. In: VI Encontro de Pesquisa em Educação da UFPI. 2010. VI Encontro de Pesquisa em Educação da UFPI, Teresina: UFPI, 2010.

\section{Correspondência}

Gabriel Moreira Beraldi — Instituto Federal Colégio Pedro II — 177, CEP 20921-903, São Cristóvão, Rio de Janeiro, Rio de Janeiro, Brasil.

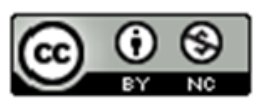

This work is licensed under a Creative Commons Attribution-NonCommercial 4.0 International (CC BY-NC 4.0)

\section{Notas}

\footnotetext{
${ }^{1}$ A presente pesquisa foi desenvolvida como parte da pesquisa de Mestrado de XXXXX, sendo aprovada pelo Comitê de Ética designado pela Plataforma Brasil sob o número de parecer 2.295.753.
} 